\title{
$\mathrm{BiTiO}_{3}$ 첨가에 따른 $\left(\mathrm{Na}_{0.5} \mathrm{~K}_{0.5}\right) \mathrm{NbO}_{3}$ 세라믹스의 구조적, 전기적 특성
}

\begin{tabular}{|c|}
\hline 논 문 \\
\hline $60-11-15$ \\
\hline
\end{tabular}

\section{Structural and Electrical Properties of $\left(\mathrm{Na}_{0.5} \mathrm{~K}_{0.5}\right) \mathrm{NbO}_{3}$ Ceramics with Addition of $\mathrm{BiTiO}_{3}$}

\author{
이 태 호** 김 대 영***조 서 현**.정 광 호** 이 성 갑 ${ }^{\dagger}$
}

(Tae Ho Lee $\cdot$ Dae Young Kim $\cdot$ Seo Hyeon Jo $\cdot$ Gwang-Ho Jeong $\cdot$ Sung-Gap Lee)

\begin{abstract}
In this study, lead-free $\left(\mathrm{Na}_{0.5} \mathrm{~K}_{0.5}\right) \mathrm{NbO}_{3}-\mathrm{BiTiO}_{3}$ ceramics were fabricated by a conventional mixed oxide method. Structural and electrical properties of lead-free $\left(\mathrm{Na}_{0.5} \mathrm{~K}_{0.5}\right) \mathrm{NbO}_{3}$ ceramics with the variation of $\mathrm{BiTiO}{ }_{3}$ were investigated. The results of $\mathrm{X}$-ray diffraction analysis showed a typical polycrystalline perovskite structure without presence of the second phase in all specimens. Sintered density increased with an increasing of BTO and the specimen added with $0.07 \mathrm{~mol} \%$ of $\mathrm{BiTiO}_{3}$ showed the maximum value of $97.8 \%$. Average grain size decreased and densification increased with an increasing of $\mathrm{BiTiO}_{3}$ contents. The electromechanical coupling factor of the $0.01 \mathrm{~mol} \% \mathrm{BiTiO}_{3}$ doped

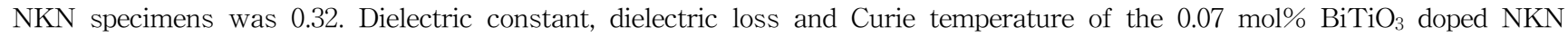
specimens were $1185,0.145 \%$ and $400^{\circ} \mathrm{C}$, respectively.
\end{abstract}

Key Words : Electrical properties, NKN, BTO, Piezoelectric, Dielectric constant

\section{1. 서 론}

현대 전자 산업의 발전은 그 구성 재료인 부품소재에 크 게 의존하고 있으며, 부품소재의 발달이 전자산업을 이끌어 가고 있다하여도 과언이 아니다[1]. 부품 소재 중에서 압전 세라믹 재료는 소재에 인가된 기계적 에너지가 전기적 에너 지로 또는 그 역으로 변환하는 압전성(piezoelectricity)을 나 타내는 재료로서, 초음파센서, 압전 변압기, 액츄에이터, 필 터, 레조네이터 등과 같은 여러 분야에서 이용되고 있으며, 특성 향상을 위한 많은 연구가 진행되고 있다 [2-4]. 현재 일반적으로 활용되고 있는 대표적인 압전 세라믹 재료로는 $\mathrm{Pb}(\mathrm{Zr}, \mathrm{Ti}) \mathrm{O}_{3}$ (PZT) 물질이다[5]. $\mathrm{PZT}$ 는 조성 및 불순물 첨 가에 따른 우수한 압전특성을 나타내는 재료이지만, 기본 조 성에 인체에 유해한 납 $(\mathrm{Pb})$ 성분을 포함하고 있으며, 최근 환경문제에 대한 우려로 인해 이에 대한 대체물질의 개발이 시급한 실정이다. 최근 $\mathrm{PZT}$ 를 대체할 무연계 (lead-free) 압 전 세라믹스 물질로 $\mathrm{BaTiO}_{3}(\mathrm{BT}), \mathrm{SrBi}_{2} \mathrm{Ta}_{2} \mathrm{O}_{9}(\mathrm{SBT}),(\mathrm{Bi}, \mathrm{Na})$ $\mathrm{TiO}_{3}(\mathrm{BNT})$ 및 $(\mathrm{Na}, \mathrm{K}) \mathrm{NbO}_{3}(\mathrm{NKN})$ 등 다양한 물질에 대 한 많은 연구가 진행되고 있다[6-8]. 특히 $\mathrm{NKN}$ 계 세라믹스 는 높은 상전이 특성과 우수한 전기기계 결합계수를 가지고 있어, 최근 비납계 압전체 재료의 대체 물질로서 주목을 받 고 있는 재료이다. 그러나 기본 조성의 $\mathrm{Na}\left(\mathrm{T}_{\mathrm{b} . \mathrm{p} .}=1177 \mathrm{~K}\right)$ 와 $\mathrm{K}\left(\mathrm{T}_{\text {b.p. }}=1043 \mathrm{~K}\right)$ 성분은 공기중의 수분을 흡수하는 조해성

* 준 회 원 : 경상대 공대 세라믹 공학과

** 준 회 원 : 경상대 공대 세라믹 공학과 석사과정

† 교신저자, 시니어회원 : 경상대 공학원 세라믹 공학과 교수

E-mail :1sgap@gnu.ac.kr

접수일자 : 2011년 9월 26일

최종완료 : 2011년 10월 25일
과 시편 제조 시 낮은 분해온도로 인해 휘발되는 단점을 가 지고 있다. 따라서 $\mathrm{NKN}$ 물질의 압전 세라믹 재로로의 응용 을 위해, 시편 제작시 $\mathrm{Na}, \mathrm{K}$ 원소의 휘발 억제와 소결밀도 를 높이기 위한 방향으로 연구가 진행되었으며, 이를 이해 다양한 불순물 및 $\mathrm{SrTiO}_{3}, \mathrm{BaTiO}_{3}, \mathrm{LiTaO}_{3}$ 등의 화합물을 첨가 한 고용체를 제작하여 구조적, 전기적 특성을 조사하였 다. 본 연구에서는 $\mathrm{NKN}$ 세라믹스의 소결밀도향상에 따른 우수한 구조적, 전기적 특성을 얻기 위해 $\mathrm{BiTiO}_{3}$ (BTO)를 고용시킨 NKN-BTO 시편을 일반소성법으로 제작하였으며, 첨가량에 따른 구조적, 전기적 특성을 측정하여 실용소자로 의 응용 가능성에 대해 조사하였다.

\section{2. 실험 방법}

본 실험에서는 $\mathrm{NKN}-\mathrm{BTO}$ 시편 제작을 위해 $\mathrm{Na}_{2} \mathrm{CO}_{3}$ (99\%), $\mathrm{K}_{2} \mathrm{CO}_{3}(99 \%), \mathrm{Nb}_{2} \mathrm{O}_{5}(99 \%), \mathrm{Bi}_{2} \mathrm{O}_{3}(99 \%), \mathrm{TiO}_{2}(99 \%)$ 를 원료 물질로 사용하였으며, $(1-x)(\mathrm{Na}, \mathrm{K}) \mathrm{NbO}_{3}-x \mathrm{BiTiO}_{3}$ 조성 식에 따라 BTO 첨가량을 $0.01 \sim 0.07 \mathrm{~mol} \%$ 변화시켰다. 먼 저 시료를 전자저울을 이용하여 칭량 한 후, 에틸알콜을 분 산매로 하여 지르코니아 $\left(\mathrm{ZrO}_{2}\right)$ 볼을 사용하여 24시간 동안 혼합분쇄 하였다. 혼합 분쇄한 시료를 $100^{\circ} \mathrm{C}$ 에서 24 시간동안 건조시킨 후 알루미나 도가니로 $950{ }^{\circ} \mathrm{C}$ 에서 2 시간 하소 하였 다. 하소한 분말은 다시 분쇄하고 $\mathrm{PVA}$ 를 $3 \mathrm{wt} \%$ 만큼 섞어 혼합 하였다. 혼합한 시료를 원통형 몰더 $(\Phi=12 \mathrm{~mm})$ 에 넣 고, $1000 \mathrm{~kg} / \mathrm{cm}^{2}$ 의 압력으로 일축 가압 성형하였으며, 일축 가압된 시편은 $\mathrm{CIP}$ (cold isostatic press)를 이용해 $30 \mathrm{MPa}$ 의 압력을 가해주었다. 시편의 소결조건은 $1110^{\circ} \mathrm{C}$ 에서 2 시간 으로 하였다. 소결된 시편은 $0.5 \mathrm{~mm}$ 의 두께로 연마하였으며, 스크린 프린팅법을 이용하여 $\mathrm{Ag}$ 전극을 형성한 후 $600^{\circ} \mathrm{C}$ 에 서 10 분간 열처리하였다. 시편의 전기적 특성을 측정하기 위 
해 모든 시편에 대해 $30 \mathrm{kV} / \mathrm{cm}$ 의 직류전계를 30 분간 인가 하여 분극처리를 행하였다. 미세구조 및 결정 구조를 분석하 기위해 $\mathrm{SEM}$ (scanning electron microscope)과 XRD ( $\mathrm{x}$-ray diffraction)를 이용해 관찰하였으며, LCR 메타(Fluke 6306, $\mathrm{USA}$ )를 사용하여 유전 특성을 측정하였다.

\section{3. 결과 및 고찰}

그림 1 은 $\mathrm{NKN}$ 세라믹스에 $\mathrm{BiTiO}_{3}$ 의 첨가량에 따른 $\mathrm{X}-$ 선 회절 분석을 나타낸 것이다. 모든 시편은 전형적인 다결 정성 페로브스카이트 구조를 나타내었으며, 우선 배향성과 2 차상 또는 미반응 물질 등은 관찰되지 않았다. 그림 2 는 $2 \Theta$

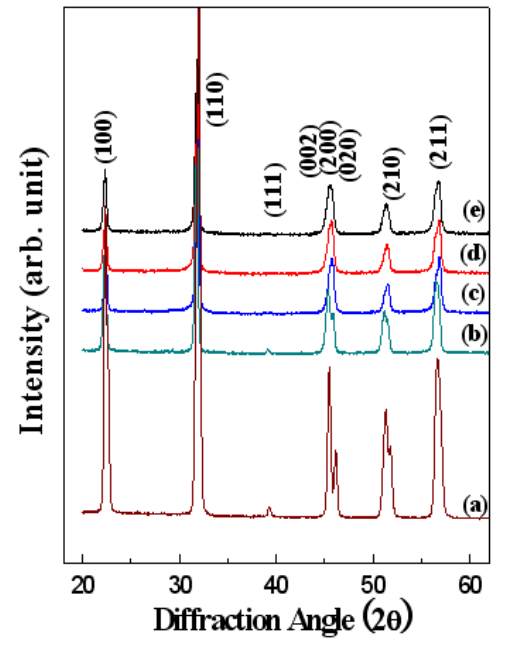

그림 $11-x\left(\mathrm{Na}_{0.5} \mathrm{~K}_{0.5}\right) \mathrm{NbO}_{3}-\mathrm{xBiTiO}_{3}$ 시편의 $\mathrm{X}$-선 회절 모양: :

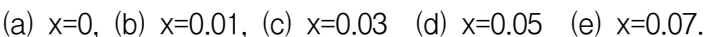

Fig. 1 XRD patterns of $1-x\left(\mathrm{Na}_{0.5} \mathrm{~K}_{0.5}\right) \mathrm{NbO}_{3}-x \mathrm{BiTiO}$ specimens: (a) $x=0$, (b) $x=0.01$, (c) $x=0.03$ (d) $x=0.05 \quad$ (e) $x=0.07$.

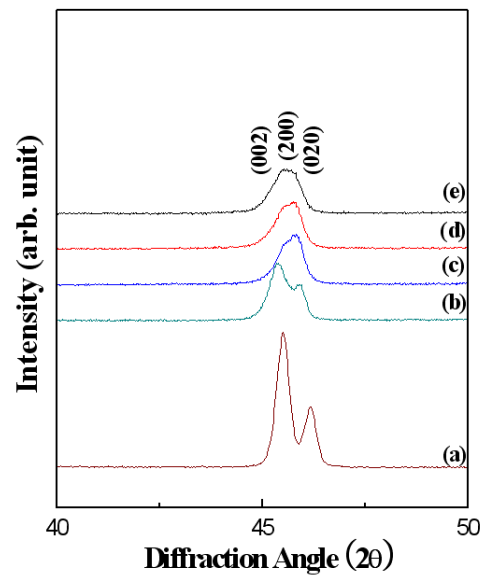

그림 $22 \theta=40 \sim 50^{\circ}$ 부근에서 $1-x\left(\mathrm{Na}_{0.5} \mathrm{~K}_{0.5}\right) \mathrm{NbO}_{3}-\mathrm{xBiTiO}_{3}$ 시편의 $x$-선 회절 모양: (a) $x=0$, (b) $x=0.01$, (c) $x=$ $0.03 \quad$ (d) $x=0.05$ (e) $x=0.07$.

Fig. $2 \times R D$ pattern of $1-x\left(\mathrm{Na}_{0.5} \mathrm{~K}_{0.5}\right) \mathrm{NbO}_{3}-\mathrm{xBiTiO}_{3}$ specimens in the range of $2 \Theta=40 \sim 50^{\circ}$ : (a) $x=0$, (b) $x=0.01$, (c) $x=0.03 \quad$ (d) $x=0.05 \quad$ (e) $x=0.07$
$=44 \sim 46^{\circ}$ 부근의 피크를 확대한 것으로, 순수한 $\mathrm{NKN}$ 에서는 전형적인 정방정계상의 $(002) /(200)$ 피크 분리가 관찰되었다. 그러나 BTO의 첨가량이 증가함에 따라 $(002) /(200)$ 피크는 단일 피크로 변화되었으며, 이는 첨가된 $\mathrm{BTO}$ 원소가 $\mathrm{NKN}$ 의 기본 구조에 혼입함에 따른 결정구조의 변화에 기인한 것으로 판단된다.

그림 3은 $\mathrm{NKN}$ 세라믹스에 $\mathrm{BTO}$ 첨가량에 따른 표면 미 세구조를 나타낸 것이다. $\mathrm{BTO}$ 첨가량이 증가 할수록 평균 결정립의 크기가 감소하고 미세구조가 치밀해지는 것을 알 수 있다. 이는 첨가된 낮은 융점을 갖는 $\mathrm{BTO}$ 물질이 일부 는 $\mathrm{NKN}$ 기본 조성과 치환하고, 일부는 결정입계층에 분포 함에 따라 $\mathrm{Na}, \mathrm{K}$ 원소의 휘발 억제 및 치밀화를 향상시킨 것으로 판단된다.
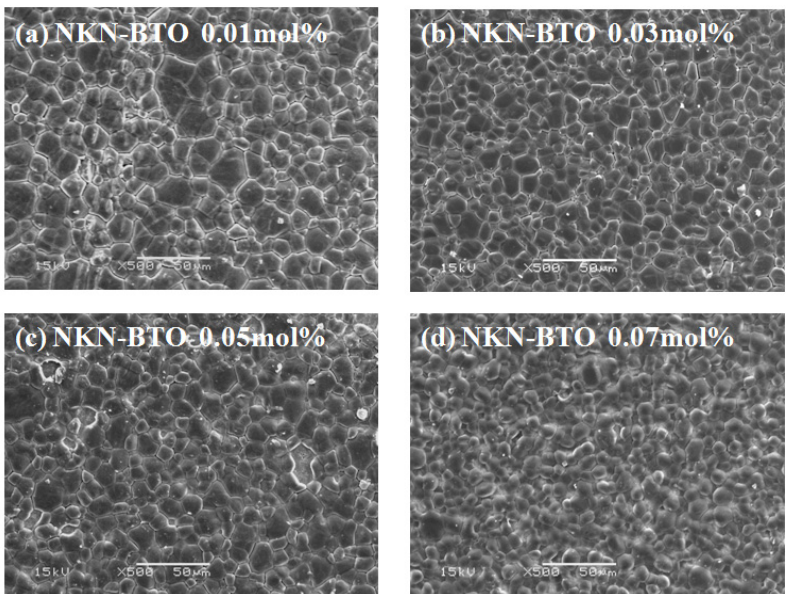

그림 $31-x\left(\mathrm{Na}_{0.5} \mathrm{~K}_{0.5}\right) \mathrm{NbO}_{3}-\mathrm{xBiTiO}_{3}$ 시편의 표면 미세구조: $\begin{array}{llll}\text { (a) } x=0.01 & \text { (b) } x=0.03 & \text { (c) } x=0.05 & \text { (d) } x=0.07\end{array}$

Fig. 3 Surface microstructure of $1-x\left(\mathrm{Na}_{0.5} \mathrm{~K}_{0.5}\right) \mathrm{NbO}_{3}-x \mathrm{BiTiO}_{3}$ specimens: (a) $x=0.01$ (b) $x=0.03$ (c) $x=0.05$ (d) $x=0.07$

그림 4는 $\mathrm{NKN}$ 세라믹스의 $\mathrm{BTO}$ 첨가량에 따른 소결밀 도와 상대밀도를 나타낸 그래프이다. BTO 첨가량이 증가할 수록 시편의 소결밀도가 증가하는 특성을 나타내었으며, $0.07 \mathrm{~mol} \%$ 첨가한 경우 이론밀도의 약 $97.8 \%$ 의 양호한 특성

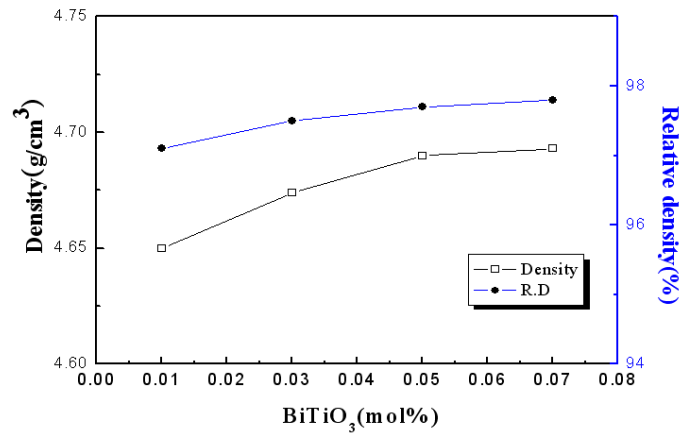

그림 $41-x\left(\mathrm{Na}_{0.5} \mathrm{~K}_{0.5}\right) \mathrm{NbO}_{3}-\mathrm{xBiTiO}_{3}$ 시편의 소결밀도 및 상대 밀도: (a) $x=0.01$, (b) $x=0.03$ (c) $x=0.05$ (d) $x=0.07$.

Fig. 4 Sintered and relative density of $1-x\left(\mathrm{Na}_{0.5} \mathrm{~K}_{0.5}\right) \mathrm{NbO}_{3}-$ $\mathrm{xBiTiO}_{3}$ specimens: (a) $\mathrm{x}=0.01$, (b) $\mathrm{x}=0.03$ (c) $\mathrm{x}=0.05$ (d) $\mathrm{x}=0.07$. 
을 나타내었다. 이러한 특성은 그림 3의 표면 미세구조에서 나타난 바와 같이 $\mathrm{BTO}$ 첨가량이 증가함에 따라 $\mathrm{Na}, \mathrm{K}$ 원 소의 휘발 억제 및 치밀도 향상에 기인한 것으로 판단된다.

그림 5 는 $\mathrm{NKN}$ 세라믹스에 $\mathrm{BTO}$ 의 첨가량에 따른 전기기 계 결합계수 $\left(\mathrm{k}_{\mathrm{p}}\right)$ 를 나타낸 것이다. $\mathrm{BTO}$ 첨가량이 0.01 $\mathrm{mol} \%$ 일 때 전기기계결합계수는 0.32 로 최대값을 나타내었 으며, 그 이상의 첨가한 경우에는 점차 감소하는 경향을 나 타내었다. 이는 페로브스카이트 구조를 갖는 $\left(\mathrm{Na}_{0.5} \mathrm{~K}_{0.5}\right) \mathrm{NbO}_{3}$ 조성의 $\mathrm{A}$-자리에 있는 $\mathrm{Na}^{+}(0.95 \AA)$ 이온에 상대적으로 큰 이 온반경을 가지는 $\mathrm{Bi}^{3+}(1.20 \AA)$ 이온이 치환됨에 따라 단위격자 가 왜곡됨에 따라 $\mathrm{B}$-자리 $\mathrm{Nb}^{5+}$ 이온의 변위공간이 감소하 였기 때문으로 판단된다.

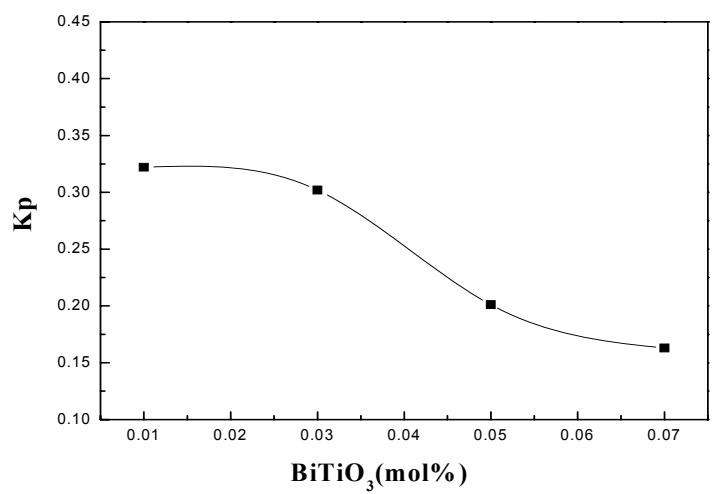

그림 $51-x\left(\mathrm{Na}_{0.5} \mathrm{~K}_{0.5}\right) \mathrm{NbO}_{3}-\mathrm{xBiTiO}_{3}$ 시편의 $\mathrm{BiTiO}_{3}$ 첨가량에 따른 전기기계 결합계수 $\left(\mathrm{K}_{\mathrm{p}}\right)$

Fig. 5 Electromechanical coupling factor $\left(\mathrm{K}_{\mathrm{p}}\right)$ of $1-\mathrm{x}\left(\mathrm{Na}_{0.5} \mathrm{~K}_{0.5}\right)$ $\mathrm{NbO}_{3}-\mathrm{xBiTiO}_{3}$ specimens with variation of $\mathrm{BiTiO}_{3}$ contents.

그림 6 은 $\mathrm{NKN}$ 세라믹스의 $\mathrm{BTO}$ 첨가량에 따른 유전 상 수와 유전손실을 나타낸 것이다. $\mathrm{BTO}$ 첨가량이 증가함에 따라 유전상수와 유전손실이 증가하는 특성을 나타내었다. 그림 3 의 미세구조와 비교하여 볼 때, $\mathrm{BTO}$ 첨가량이 증가

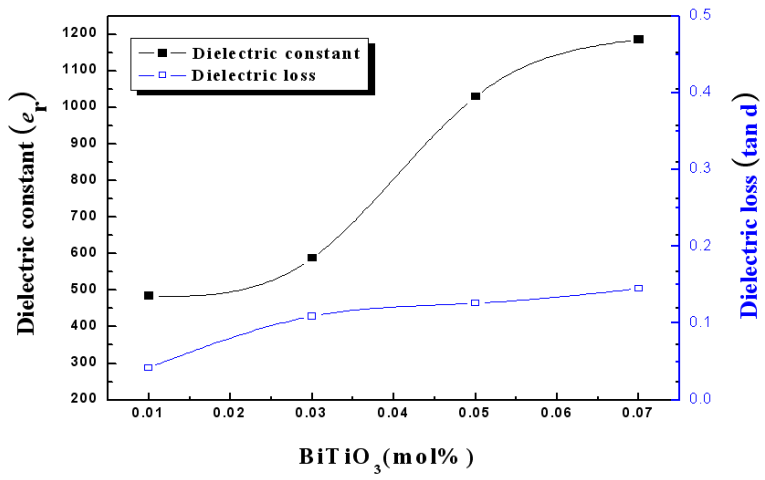

그림 $61-x\left(\mathrm{Na}_{0.5} \mathrm{~K}_{0.5}\right) \mathrm{NbO}_{3}-\mathrm{xBiTiO}_{3}$ 시편의 $\mathrm{BiTiO}_{3}$ 첨가량에 따른 유전상수 및 유전손실

Fig. 6 Dielectric constant and dielectric loss of $1-x\left(\mathrm{Na}_{0.5} \mathrm{~K}_{0.5}\right)$ $\mathrm{NbO}_{3}-\mathrm{xBiTiO}_{3}$ specimens with variation of $\mathrm{BiTiO}_{3}$ contents.
함에 따라 평균 결정립의 크기가 감소함에도 불구하고 유전 상수가 증가한 것은 $\mathrm{BTO}$ 의 첨가에 의해 낮은 분해온도를 갖는 $\mathrm{Na}, \mathrm{K}$ 원소의 휘발이 억제됨에 따른 미세구조의 치밀 성에 기인한 것으로 판단된다. 따라서 본 연구를 통해 시편 의 유전상수 특성에 대해 결정립의 크기보다는 시편 내부에 분포한 미세 기공이 더욱 큰 영향을 미친다는 것을 알 수 있었다. 유전손실특성은 $\mathrm{BTO}$ 첨가량이 증가함에 따라 조금 증가하는 경향을 나타내었으며, 이는 비정질 결정구조를 갖 는 결정입계층의 분포가 증가하였기 때문으로 생각된다. 그 러나 모든 시편에서 0.2 이하의 매우 양호한 특성을 나타내 었다.

그림 7은 $\mathrm{NKN}$ 세라믹스의 $\mathrm{BTO}$ 첨가량 및 온도 변화에 따른 유전상수를 나타낸 것이며, 모든 시편에서 상전이온도 부근에서 급격한 상전이 특성을 나타내었다. $\mathrm{BTO}$ 첨가량이 증가함에 따라 상전이 온도는 감소하는 경향을 나타내었으 며, $0.07 \mathrm{~mol} \%$ 첨가된 시편에서 약 $400^{\circ} \mathrm{C}$ 의 큐리온도를 나 타내었다. 이는 첨가된 $\mathrm{BTO}$ 물질의 일부가 $\mathrm{NKN}$ 조성과 치환함에 의한 단위격자 구조내 $\mathrm{B}$-자리 이온의 변위 억제 및 저유전상의 $\mathrm{BTO}$ 조성이 결정입계층에 분포함에 기인한 것으로 판단된다.

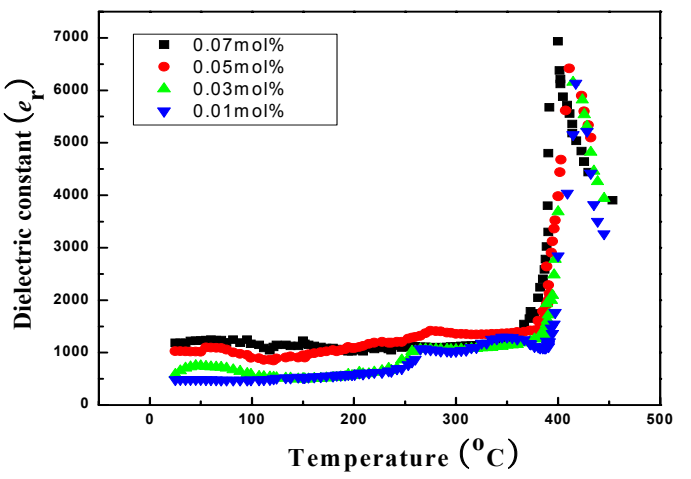

그림 $71-\mathrm{x}\left(\mathrm{Na}_{0.5} \mathrm{~K}_{0.5}\right) \mathrm{NbO}_{3}-\mathrm{xBiTiO}_{3}$ 시편의 $\mathrm{BiTiO}_{3}$ 첨가량 및 온도에 따른 유전상수

Fig. 7 Dielectric constant of $1-x\left(\mathrm{Na}_{0.5} \mathrm{~K}_{0.5}\right) \mathrm{NbO}_{3}-\mathrm{xBiTiO}_{3}$ specimens with variation of $\mathrm{BiTiO}_{3}$ contents and temperature.

\section{4. 결 론}

본 논문에서는 $\mathrm{NKN}$ 세라믹스의 저온 소결 및 치밀성 증 대를 위해 $\mathrm{BTO}$ 물질을 첨가하였으며, 첨가량에 따른 구조 적, 전기적 특성을 조사하여 다음과 같은 결과를 얻었다.

1. $\mathrm{BTO}$ 첨가량이 증가함에 따라 $\mathrm{NKN}$ 시편의 소결밀도는 증가하는 경향을 나타내었으며, $0.07 \mathrm{~mol} \%$ 첨가한 시편 에서 최대 $97.8 \%$ 의 양호한 특성을 얻었다.

2. 시편의 전기기계 결합계수는 $\mathrm{BFO}$ 를 $0.01 \%$ 첨가한 시편 에서 0.32 의 최대값을 나타내었다.

3. $\mathrm{BTO}$ 첨가량이 증가함에 따라 유전상수와 유전손실은 증 가하는 경향을 나타내었으며, $0.07 \mathrm{~mol} \%$ 첨가한 시편에 서 각각 1185 와 $0.145 \%$ 의 양호한 특성을 얻었다. 
4. $\mathrm{BTO}$ 첨가량이 증가함에 따라 상전이온도는 감소하였으 며, $0.07 \mathrm{~mol} \%$ 첨가한 시편에서 $400^{\circ} \mathrm{C}$ 의 특성을 나타내 었다.

\section{감사의 글}

본 연구는 2011년 정부 (교육인적자원부)의 재원으 로 한국학술진흥재단의 지원을 받아 수행된 연구임 (KRF-03-2011-0223)

\section{참 고 문 헌}

[1] Seung-Ho Park, Cheol-woo Ahn, Sahn Nahm and Jae-Sung Song, "Microstructure and Piezoelectric Properties of $\mathrm{ZnO}$-added $\left(\mathrm{Na}_{0.5} \mathrm{~K}_{0.5}\right) \mathrm{NbO}_{3}$ Ceramics", The japan Society of Applied Physics, Vol. 43, pp. L1072-L1074, 2004

[2] Ruzhong Zuo, Jurgen Rodel Renzheng Cen, and Longtu $\mathrm{Li}$, "Sintering and Electrical Properties of Lead-Free $\mathrm{Na}_{0.5} \mathrm{~K}_{0.5} \mathrm{NbO}_{3}$ Piezoelectric Ceramics”, J. Am. Ceram. Soc., 89[6], 2010-2015, 2006.

[3] Bao-Quan Min, Jin-Feng Wang, Peng Qi, and GuoZhong Zang, "Piezoelectric Properties of ( $\mathrm{Li}, \mathrm{Sb}, \mathrm{Ta}$ ) modified ( $\mathrm{Na}, \mathrm{K}) \mathrm{NbO}_{3}$ lead-free ceramics", Journal of Applied Physics, 101, 054103, 2007.

[4] Young-Hyeok Kim, Dae-Young Heo, Weon-Pil Tai, and Jae-Shin Lee, "Effects of High Energy Ball Milling on the Piezoelectric Proreries of Lead-free $\left(\mathrm{K}_{0.44 \mathrm{Na}}{ }_{0.52}\right)$ $\left(\mathrm{Nb}_{0.86} \mathrm{Ta}_{0.10}\right)-0.04 \mathrm{LiSbO}_{3}$ Ceramics", Journal of the Korean Ceramic Society, Vol.45, No.6, pp. 363-367, 2008.

[5] Y. Xu, "Ferroelectric materials and their applications" (North holland, Amsterdam, 1911) p. 101.

[6] Sang-Ho Moon, Yong-Su Ham, Young-Hie Lee, SongMin Nam, Jung-Hyuk Koh, "The ferroelectric and piezoelectric properties of $\mathrm{Li}_{2} \mathrm{O}$-Excess $\left(\mathrm{Na}_{0.51} \mathrm{~K}_{0.47} \mathrm{Li}_{0.02}\right)$ $\left(\mathrm{Nb}_{0.8} \mathrm{Ta}_{0.2}\right) \mathrm{O}_{3}$ Ceamics", J. Korean Phys. Soc. Vol. 56, No. 1 399-401, 2010

[7] Y. Guo, K. Kakimoto, and H. Ohsato, "Phase Transitional Behavior and Piezoelectric Properties of $\mathrm{Na}_{0.5} \mathrm{~K}_{0.5} \mathrm{NbO}_{3}-\mathrm{iNbO}_{3}$ Ceramics," Appl. Phys. Lett., 85 [18] 4121-4123, 2004.

[8] R. J. Xie, Y. Akimune, R.Wang, N. Hirosaki, and T. Nishimuna, "Dielectricand Piezoelectric Properties of Barium-Substitued $\mathrm{Sr}_{1.9} \mathrm{Ca}_{0.1} \mathrm{NaNb}_{5} \mathrm{O}_{15}$ Ceramics," Jpn. J. Appl. Phys., 42 [12] $7404-74092003$.
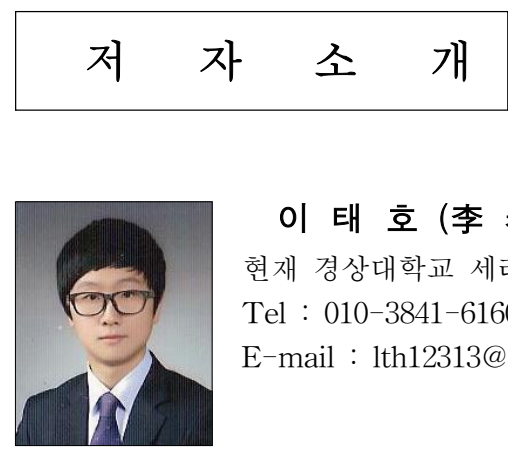

\section{이 태 호 (李 泰 昊)}

현재 경상대학교 세라믹 공학과 학부 과정 Tel : 010-3841-6160

E-mail : 1th12313@hanmail.net

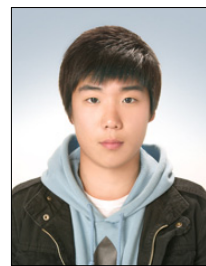

\section{김 대 영 (金 大 永)}

2011년 경상대학교 세라믹 공학과 졸업. 현재 경상대학교 세라믹 공학과 석사 과정

Tel : 010-2447-8476

E-mail : kimvsyoung@nate.com

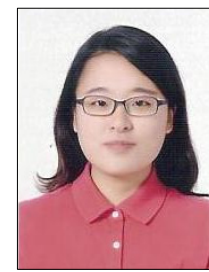

\section{조 서 현 (趙 諝 賢)}

2011년 경상대학교 세라믹 공학과 졸업. 현재 경상대학교 세라믹 공학과 석사 과정

Tel : 010-6250-1512

E-mail : musicjsh@gmail.com

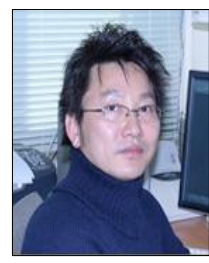

\section{이 성 갑 (李 成 甲)}

1985년 광운대학교 전자재료공학과 졸업 1987년 광운대학교 대학원 전자재료공학 과 졸업(석사), 1992년 광운대학교 대학 원 전자재료공학과 졸업(박사). 현재 경 상대학교 세라믹 공학과 교수.

Tel : 055-751-5333

E-mail : lsgap@gnu.ac.kr

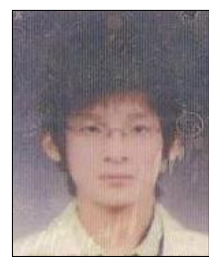

\section{정 광 호 (趙 諝 賢)}

2011년 경상대학교 세라믹 공학과 졸업. 현재 경상대학교 세라믹 공학과 석사 과정

Tel : 010-9291-3886

E-mail : anijgh@naver.com 